\title{
PROTOTIPE SISTEM CRM BERBASIS E-COMMERCE MENGGUNAKAN METODE USER CENTERED DESIGN DENGAN CODEIGNITER FRAMEWORK
}

\author{
William Frado Pattipeilohy ${ }^{1}$; Sanwani ${ }^{2}$ \\ Program Studi Sistem Informasi \\ Universitas Budi Luhur \\ http://budiluhur.ac.id \\ William.Frado@budiluhur.ac.id \\ 2Program Studi Sistem Informasi \\ STIMIK Nusa Mandiri \\ http://nusamandiri.ac.id \\ Sanwani.swq@nusamandiri.ac.id
}

\begin{abstract}
Competition in the business world is increasingly being offered in the ever-expanding internet world. The impact of the competition is increasingly rapid economic growth. Therefore companies must provide good information and services to customers and the public at large about the products to be offered. In this case so that customers can maintain and not move to other producers. There are a number of challenges in companies engaged in the sale of goods and services that are found to be still found a variety of problems, such as customers who have difficulty ordering goods outside of business hours associated with companies to serve real time customers 24 hours a day and where there are products that different different that customers still need to know more about. By accessing the E-Commerce-based customer relationship management system using the Centered User Design Method and the Codeigniter Framework facilitates an organizing system that is more ready and facilitates the transaction process. This research was conducted at PT. Anugerah Mandiri that provides information to customers in conducting online transactions and getting the latest product information updated with customers obtaining information obtained quickly and increasing the comfort of transactions.

Keywords: CRM, e-commerce, UCD, Customer, CodeIgniter Framework
\end{abstract}

Intisari-Persaingan di dunia bisnis saat ini semakin ketat apalagi dalam dunia internet yang terus berkembang. Dampak dari persaingan tersebut ialah pertumbuhan ekonomi semakin cepat. Oleh karena itu perusahaan harus memberikan informasi dan pelayanan yang baik bagi pelanggan dan masyarakat luas mengenai produk yang akan ditawarkan. Dalam hal ini agar para pelanggan bisa terjaga dan tidak berpindah ke produsen yang lain. Ada beberapa kendala pada perusahaan yang bergerak di bidang penjualan barang dan jasa diantaranya masih ditemukan berbagai masalah, seperti pelanggan sulit memesan barang diluar jam kerja perusahaan karena keterbatasan perusahaan untuk melayani pelanggan secara real time 24 jam dalam sehari dan adanya jenis produk baru yang berbeda yang masih harus lebih diketahui oleh pelanggan. Dengan pendekatan system customer relationship management berbasis E-Commerce menggunakan Metode User Centered Design dan Codeigniter Framework memudahkan dalam pengorganisasian system yang lebih teratur serta memudahkan proses transaksi. Penelitian ini dilakukan di PT. Anugerah Mandiri yang bertujuan untuk memberikan kemudahan kepada pelanggan dalam melakukan traksaksi secara online serta mendapatkan informasi produk terbaru yang terupdate sehingga pelanggan memperoleh informasi yang diinginkan dengan cepat dan meningkatkan kenyaman dalam bertransaksi.

Kata Kunci: Customer Relationship Management, e-commerce, User Centered Design, Pelanggan, CodeIgniter Framework.

\section{PENDAHULUAN}

Keberadaan internet adalah sebagai media promosi suatu produk. Suatu produk yang dionlinekan melalui internet dapat membawa keuntungan besar bagi pengusaha karena produknya di kenal di seluruh dunia.

Penggunaan internet tidak hanya terbatas pada pemanfaatan informasi yang dapat diakses melalui media ini, melainkan juga dapat digunakan sebagai sarana untuk melakukan transaksi perdagangan yang sekarang di Indonesia telah mulai diperkenalkan melalui beberapa seminar dan telah mulai penggunaannya oleh beberapa perusahaan yaitu electronic commerce atau yang lebih dikenal 
dengan E-commerce, yang merupakan bentuk perdagangan secara elektronik melalui media internet. E-commerce pada dasarnya merupakan suatu kontak transaksi perdagangan antara penjual dan pembeli dengan menggunakan media internet. Jadi proses pemesanan barang dikomunikasikan melalui internet (Walch, 2009).

Penerapan E-commerce dapat mengubah kebiasaan pelanggan yang awalnya berbelanja secara konvensional menjadi secara online. Waktu dan jarak tidak lagi menjadi masalah dalam bertransaksi, karena melalui internet pelanggan dapat bertransaksi kapanpun dan dimanapun. Sehingga perusahaan dapat memperluas jaringan pemasaran dan penjualannya (Maryama, 2018).

Kunci keberhasilan perusahaan bukan hanya terletak pada kualitas produk dan jasa, tetapi juga bagaimana cara perusahaan bisa memuaskan pelanggannya kemudian memberikan layanan yang baik dan menyenangkan mereka untuk memastikan mereka menjadi pelanggan yang setia. Oleh karena itu perusahaan harus mampu memberikan layanan yang mudah diakses, mudah digunakan dan sederhana namun bisa menjadi media pemasaran sekaligus membantu pelanggan dalam melakukan transaksi. Perusahaan semakin menyadari bahwa memahami pelanggan, merespon kebutuhan pelanggan dengan cepat dan tepat menjadi sesuatu yang penting bagi bisnis mereka. Untuk memenuhi kebutuhan tersebut, setiap perusahaan perlu mengenali pelanggannya serta bersifat proaktif dan antisipatif terhadap keinginan pelanggan.

Customer Relationship Management (CRM) adalah strategi tingkat korporasi yang mendukung suatu perusahaan untuk menyediakan pelayanan kepada pelanggan secara real time, berfokus pada pembangunan dan pemeliharaan hubungan dengan pelanggan yang memungkinkan terciptanya kesetiaan pelanggan dan menjalin hubungan dengan tiap pelanggan melalui penggunaan informasi tentang pelanggan (Baird \& Parasnis, 2011). Penerapan Customer Relationship Management dapat dikembangkan untuk memperoleh pelanggan baru, meningkatkan hubungan dengan pelanggan, dan mempertahankan pelanggan yang berujung pada terciptanya kesetian pelanggan (Kusnandar, 2011a). Customer Relationship Management berbasis sistem E-commerce, dijadikan sarana untuk meningkatkan kepuasan pelanggan dalam usaha meningkatkan penjualan.

PT. Anugerah Mandiri merupakan perusahaan yang bergerak dalam bidang perdagangan barang dan jasa, dimana jenis barang dagangan utamanya meliputi alat tulis kantor, barang cetakan buku atau majalah, alat teknik, mekanikal, elektrikal, alat telekomunikasi, alat konstruksi, komputer serta suku cadangnya. Perusahaan ini menyadari bahwa persaingan di dunia bisnis sekarang amat ketat, apalagi saat ini tingkat keuntungan bersih yang diperoleh dari pasar semakin tipis maka perusahaan harus mengetahui cara mempertahankan usahanya agar tetap terjaga.

Dalam kondisi persaingan yang ketat hal utama yang perlu diprioritaskan oleh PT. Anugerah Mandiri sebagai salah satu perusahaan yang bergerak pada bidang perdagangan agar dapat bertahan, bersaing dan meningkatkan penjualan serta adanya suatu media untuk dapat memperluas pemasarannya (Ulfah \& Rahardjo, 2013a). Hal ini mendorong PT. Anugerah Mandiri untuk mengembangkan sistem penjualan berbasis teknologi. Dengan adanya penjualan berbasis internet maka diharapkan pelanggan bisa semakin puas dan diharapkan pula penjualan bisa mengalami peningkatan. Perancangan Customer Relationship Management berbasis sistem Ecommerce untuk pelanggan, PT. Anugerah Mandiri engharapkan nilai tambah dalam model bisnisnya yang akan memperkuat nilai konpetitif perusahaan.

Tujuan Penelitian ini adalah untuk membuat Prototipe Sistem Customer Relationship Management Berbasis E-Commerce menggunakan Metode User Centered Design dengan Codeigniter Framework, yang dapat digunakan oleh PT. Anugerah Mandiri Usaha untuk membantu melakukan aktifitas bisnisnya. Dengan begitu diharapkan PT. Anugerah Mandiri dapat melayani pasar yang luas dan mampu memberikan layanan yang memudahkan pelanggannya dalam berbelanja dalam usaha meningkatkan penjualan barang dagangannya.

\section{BAHAN DAN METODE}

Perilaku konsuman adalah studi tentang unit pembelian dan proses pertukaran yang melibatkan perolehan, konsumsi, dan pembuangan barang, jasa, pengalaman serta ide-ide. Mendefinisikan perilaku konsumen yaitu sebagai proses pengambilan keputusan dan aktivitas perorang secara fisik yang dilibatkan dalam mengevaluasi, memperoleh, memakai barang-barang dan jasa baik untuk kepentingan masyarakat maupun diri sendiri (Kartikasari, Arifin, \& Hidayat, 2013).

E-commerce sering sekali mengacu kepada kegiatan menjual dan membeli melalui internet, tapi E-commerce mencakup lebih banyak dari sekedar peralatan elektronik untuk transaksi finansial antar perusahaan dengan pelanggannya. E-commerce bukan hanya mencakup pemasaran, pembelian dan penjualan melalui internet, tetapi juga meningkatkan kinerja bisnis melalui konektivitas untuk meningkatkan pelayanan dan 
mengurangi biaya, serta membuka jalur baru dan persaingan baru (Rahmidani, 2015).

Customer Relationship Management (CRM) adalah strategi yang digunakan dalam mempelajari kebutuhan dan prilaku pelanggan untuk membangun relasi yang kuat dengan pelanggan. CRM merupakan sebuah pendekatan untuk mengerti dan mempengaruhi tingkah laku pelanggan, yang dapat dilakukan melalui kemampuan berkomunikasi dalam meningkatkan pelayanan terhadap permintaan order pelanggan (Gebert, Geib, Kolbe, \& Brenner, 2003).

PHP framework merupakan suatu kerangka kerja yang telah terpola dan memudahkan pengembangan web dalam pembuatan web yang menggunakan script PHP. Semuanya sudah diatur menjadi pola-pola tertentu yang disebut dengan class yang akan meringankan programmer dalam penulisan script dan load halaman web (Supaartagorn, 2011).

CI adalah sebuah sebuah framework yang digunakan untuk membuat sebuah aplikasi berbasis web yang disusun dengan menggunakan bahasa PHP. Didalam CI terdapat beberapa macam kelas yang berbentuk library dan helper yang berfungsi untuk membantu pemrogram dalam mengembangkan aplikasinya. CI sangat mudah dipelajari oleh seorang pemrograman web pemula sekalipun. Alasannya, karena CI mempunyai file dokumentasi yang sangat memadai untuk menjelaskan setiap fungsi yang ada pada library dan helper. File dokumentasi ini disertakan secara langsung pada saat mengunduh paket framework CI (Brown, Gould, \& Foster, 2016).

\section{HASIL DAN PEMBAHASAN}

Pada tahap analisis pendahuluan ini, pertanyaan-pertanyaan yang telah diajukan kepada perusahaan mengenai rancangan dari pengembangan model sistem Customer Relationship Management (CRM) berbasis Ecommerce akan dianalisis oleh peneliti agar nantinya fitur-fitur yang dihasilkan sesuai dengan keinginan pengguna. Hal ini untuk mengetahui apakah fitur-fitur tersebut harus tersedia atau tidak dalam sistem yang akan dibangun.

Bisnis yang masih dijalankan PT. Anugerah Mandiri secara manual yaitu dengan melayani pelanggan yang melakukan pemesanan melalui telepon ataupun yang datang langsung ke perusahaan, proses transaksi yang terjadi dan memberikan nota/kwitansi sebagai bukti pembayaran, biasanya menimbulkan masalah dan terkadang menghambat proses bisnis perusahaan dan akan berdampak buruk bagi kemajuan perusahaan.

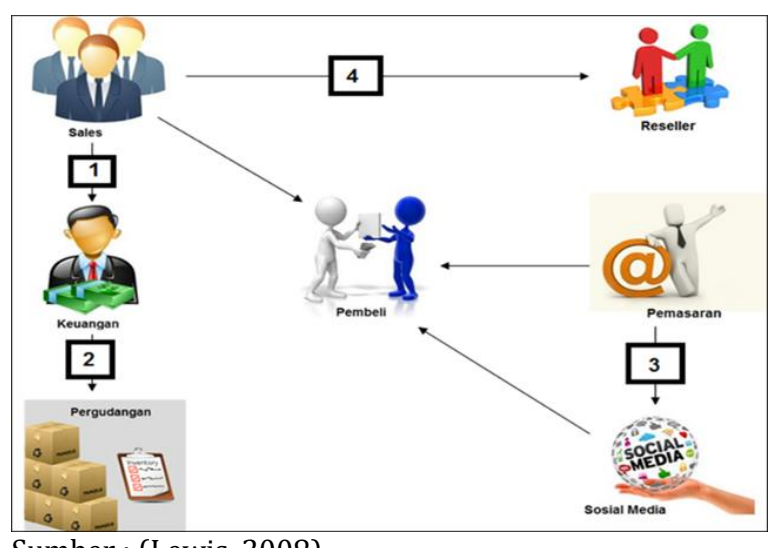

Sumber : (Lewis, 2008)

Gambar 1. Situasi Masalah Dengan Rich Picture

Dari gambar situasi masalah Rich Picture teridentifikasi 4 (empat) permasalahan yang terjadi antara lain pada point nomor 1 (satu) Bukti pembayaran dan transaksi penjualan dari penjual bisa saja hilang atau rusak sehingga tidak tercatat dengan baik oleh bagian keuangan, point nomor 2 (dua) Tidak terkontrolnya sistem pergudangan sehingga menyulitkan pencatatan data barang pada bagian keuangan dikarenakan banyak transaksi dari penjual yang hilang atau rusak, Point 3 (tiga) Bagian pemasaran tidak dapat memanfaatkan media sosial sepenuhnya untuk transaksi penjualan, tetapi hanya sebagai media promosi saja yang harus selalu di update dan point 4 (empat) Kerap terjadi kecurangan oleh penjual lainnya/reseller yang tidak jujur, sehingga dapat merugikan penjualan.

Menggambarkan proses bisnis untuk sistem yang akan diusulkan antara lain yaitu proses untuk pemesanan produk oleh anggota yang terdiri dari beberapa tahap mulai dari login sampai transaksi selesai dan produk diterima oleh customer/pelanggan. Proses tersebut dapat dilihat pada bagian perancangan model sistem $E$ commerce.

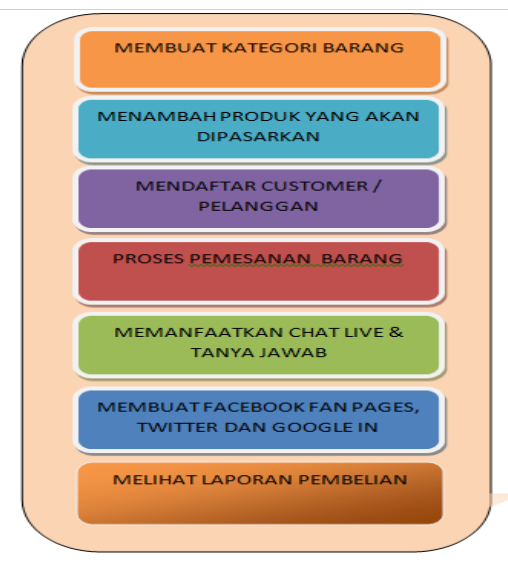

Sumber : ("E-Commerce and E-Business," 2012)

Gambar 2. Kegiatan CRM 
Proses perancangan yang dimulai dari membuat category barang sampai membuat laporan maka penulis dapat menyimpulkan mengenai requirement apa saja yang akan dikembangkan.

Proses bisnis masing-masing stakeholder sesuai dengan elemen CATWOE (Client, Actor, Transformastion, World View, Owner, Environment) . Dengan pembagian element akan mempermudah dan memperjelas tugas dari masing-masing department.

Tabel 1. Formulasi Proses Bisnis yang Relevan

\begin{tabular}{cl}
\hline Element & \multicolumn{1}{c}{ Keterangan } \\
\hline C/Client & $\begin{array}{l}\text { Member melakukan pemesanan produk } \\
\text { secara online dengan melakukan registrasi } \\
\text { sebagai anggota, menambahkan produk ke } \\
\text { shopping char. Sedangkan proses bisnis } \\
\text { untuk pengunjung hanya dapat melihat } \\
\text { catalog yang tersedia }\end{array}$ \\
\hline & $\begin{array}{l}\text { Sales melayani ketersedian barang, } \\
\text { konfirmasi pembayaran atau memberikan } \\
\text { informasi yang dibutuhkan customer. }\end{array}$ \\
A/Actor & $\begin{array}{l}\text { Marketing memberikan harga promosi, } \\
\text { untuk admin database melakukan pengelolan } \\
\text { data }\end{array}$ \\
\hline T/Transfor & $\begin{array}{l}\text { Kebutuhan model bisnis yang dapat } \\
\text { membangun sistem baru yaitu aplikasi E- } \\
\text { commerce baru untuk perusahaan yang fapat } \\
\text { memudahkan customer melakukan } \\
\text { pencarian informasi produk dan bertransaksi } \\
\text { secara online }\end{array}$ \\
\hline W/World & $\begin{array}{l}\text { Pemodelan sistem ini diharapkan dapat } \\
\text { diteraapkan untuk membanggun E-commer e } \\
\text { yang berkualitas dan terpercaya sehingga } \\
\text { mampu meraih bannyak pelanggan }\end{array}$ \\
\hline 0/Owner & $\begin{array}{l}\text { Pemeilik perusahaan yang membiayai } \\
\text { seluruh pembuatan aplikasi E-commerce }\end{array}$ \\
\hline E/Environm & $\begin{array}{l}\text { Mercant bank yang bekerja sama dengan } \\
\text { perusahaan dalam melakukan pembayaran } \\
\text { secara online }\end{array}$ \\
\hline Sumber: (Supaartagorn, 2011)
\end{tabular}

Tabel 2. Requirement Sistem yang akan Dikembangkan

\begin{tabular}{cl}
\hline No & \multicolumn{1}{c}{ Functional Requirment } \\
\hline 1 & Profil Perusahaan \\
\hline 2 & Pendaftaran anggota \\
\hline 3 & $\begin{array}{l}\text { Fasilitas integrasi dengan situs jejaring sosial seperti } \\
\text { facebook, twiter, dan google in }\end{array}$ \\
\hline 4 & Fasilitas administrator untuk update data \\
\hline 5 & Informasi cara pemesanan \\
\hline 6 & Informasi cara pembayaran \\
\hline 7 & Informasi jasa pengiriman dan tarifnya \\
\hline 8 & Konfirmasi proses pengiriman via email \\
\hline 10 & Link bank merchant atau dengan e-banking \\
\hline 11 & Fasilitas live email untuk customer service 24 jam \\
\hline 12 & Online catalog dan promotion catalog yang menarik \\
\hline
\end{tabular}

Sumber: (Ulfah \& Rahardjo, 2013a)
Pemodelan proses digunakan untuk memodelkan bisnis proses berdasarkan perspektif pengguna sistem. Pemodelan proses dapat dilihat dari Customer Relationship Management (CRM) saat ini dan Customer Relationship Management (CRM) yang ideal atau yang lebih meningkatkan penjualan. proses pemodelan dari model sistem Customer Relationship Management (CRM) berbasis E-commerce yang akan dikembangkan.
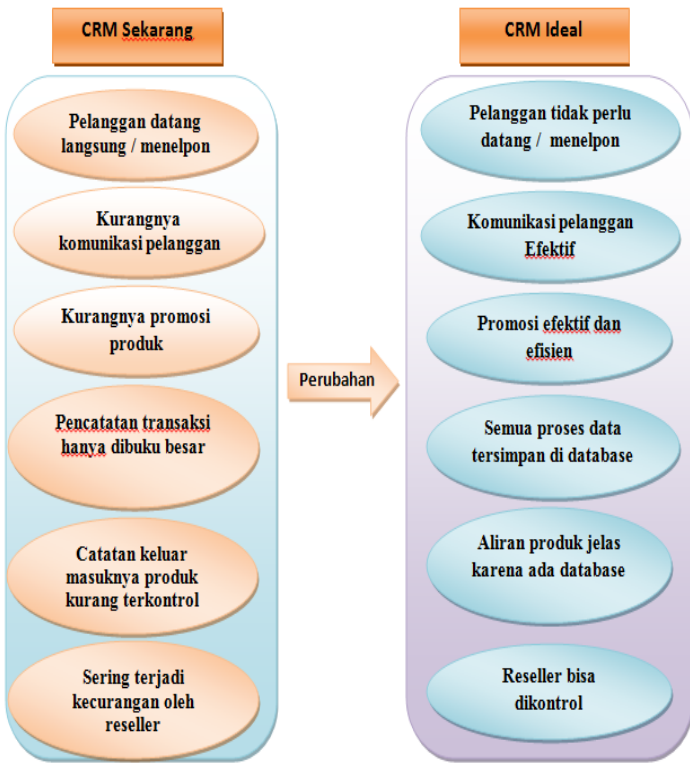

Sumber : (Kusnandar, 2011b)

Gambar 3. Pemodelan proses yang diusulkan

Pada tahap analisis pemodelan sistem, telah diuraikan proses bisnis untuk sistem yang akan diusulkan jika dibandingkan dengan keadaan sistem sebelumnya yang masih bersifat manual, maka dampak setelah pengembangan model sistem Customer Relationship Management berbasis E-commerce terhadap keadaan sesungguhnya pada sistem yang sedang berjalan.

Tabel 3. Spesifikasi Hardware dan Software

\begin{tabular}{cl}
\hline & \multicolumn{1}{c}{ Spesifikasi minimal } \\
\hline Processor & Kecepatan 2.00 GHz \\
\hline Memory & 2GB \\
\hline Hardisk & $160 \mathrm{~GB}$ \\
\hline Jaringan & LAN dan Koneksi internet \\
\hline Perangakaat & Keyboard mouse dan monitor \\
\hline Sistem Operasi & Windows 7 \\
\hline Web Browser & $\begin{array}{l}\text { Mozilla, Google Chrome, Internet } \\
\text { Explorer, Opera }\end{array}$ \\
\hline Xampp & Apache, PHP
\end{tabular}

Sumber : (Kusnandar, 2011b) 
Tabel 4. Perbandingan Real World dengan Model Konseptual

\begin{tabular}{|c|c|c|}
\hline No & Real World & Model Konspetual \\
\hline 1 & $\begin{array}{l}\text { Pelanggan } \\
\text { harus datang } \\
\text { langsung atau } \\
\text { menelpon ke } \\
\text { perusahaan } \\
\text { untuk membeli } \\
\text { produk }\end{array}$ & $\begin{array}{l}\text { Pelanggan tidak perlu lagi } \\
\text { menelpon ke perusahaan } \\
\text { untuk mengetahui produk } \\
\text { terbaru, membeli produk } \\
\text { atau hanya membandingkan } \\
\text { harga produk }\end{array}$ \\
\hline 2 & $\begin{array}{l}\text { Komunikasi } \\
\text { dengan } \\
\text { pelanggan }\end{array}$ & $\begin{array}{l}\text { Komunikasi dengan } \\
\text { pelanggan lebih mudah } \\
\text { karenas istem bisa diakses } \\
24 \text { jam }\end{array}$ \\
\hline 3 & $\begin{array}{l}\text { Promosi dan } \\
\text { pemesanan }\end{array}$ & $\begin{array}{l}\text { Dengan e-commerce dapat } \\
\text { mempermudah dalam } \\
\text { melakukan promosi } \\
\text { mengurangi biaya pemesaran }\end{array}$ \\
\hline 4 & $\begin{array}{l}\text { Nota } \\
\text { Pembayaran } \\
\text { dan transaksi } \\
\text { pembelian } \\
\text { dicatat dengan } \\
\text { benar }\end{array}$ & $\begin{array}{l}\text { Transaksi pembelian, data } \\
\text { anggota dan data order } \\
\text { tersimpan di database system } \\
\text { sehingga pembuatan laporan } \\
\text { lebih mudah }\end{array}$ \\
\hline 5 & $\begin{array}{l}\text { Catatan keluar } \\
\text { masuknya } \\
\text { produk dari } \\
\text { gudang kurang } \\
\text { terkontrol } \\
\end{array}$ & $\begin{array}{l}\text { Dengan system online produk } \\
\text { lebih jelas dan produk } \\
\text { tersimpan di dalam database } \\
\text { sistem }\end{array}$ \\
\hline 6 & $\begin{array}{l}\text { Sering terjadi } \\
\text { kecurangan } \\
\text { oleh penjual } \\
\text { yang tidak jujur }\end{array}$ & $\begin{array}{l}\text { Dengan system reseller } \\
\text { penjua bisa dikontrol karena } \\
\text { system dilengkapi dengan } \\
\text { hak akses system sehingga } \\
\text { traksaksi tetap terjadi tanpa } \\
\text { kecurangan }\end{array}$ \\
\hline
\end{tabular}

\section{Tampilan Interface Sistem E-Commerce}

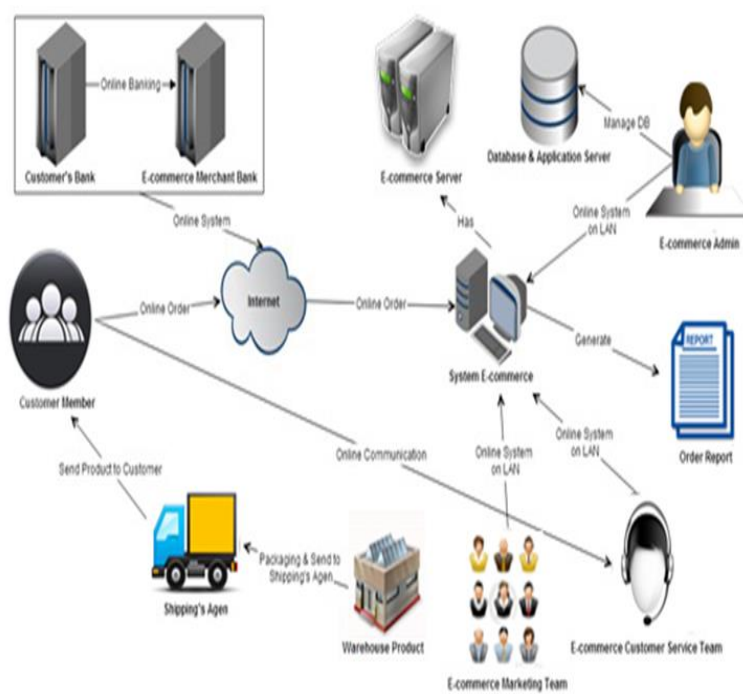

Sumber : (Dijkman, Sprenkels, Peeters, \& Janssen, 2015)

Gambar 5. Arsitektur Sistem E-commerce yang Diusulkan
Interface atau antar muka merupakan tampilan dari suatu aplikasi atau sistem yang berperan sebagai media komunikasi yang yang berhubungan langsung dengan pengguna (user).

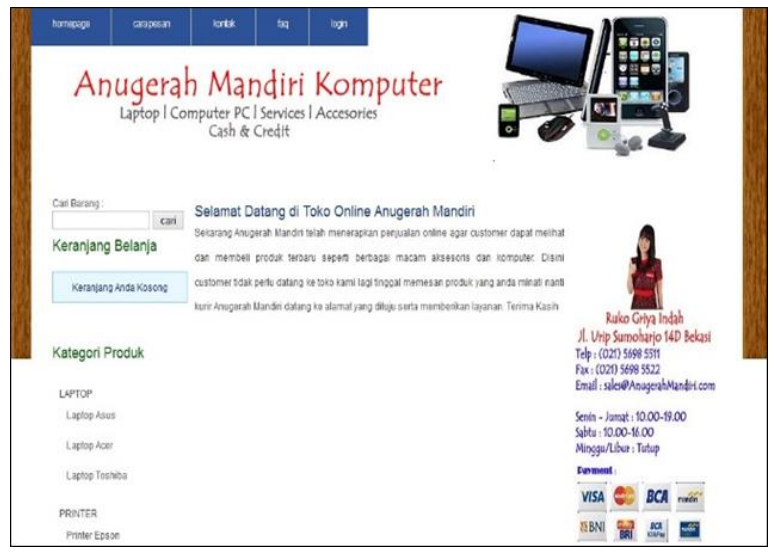

Sumber : (Kusnandar, 2011b)

Gambar 6. Halaman utama sistem E-commerce

Pengunjung bisa melakukan pencarian barang dan memilih beberapa kategori produk yang diinginkan serta keterangan proses pembayar

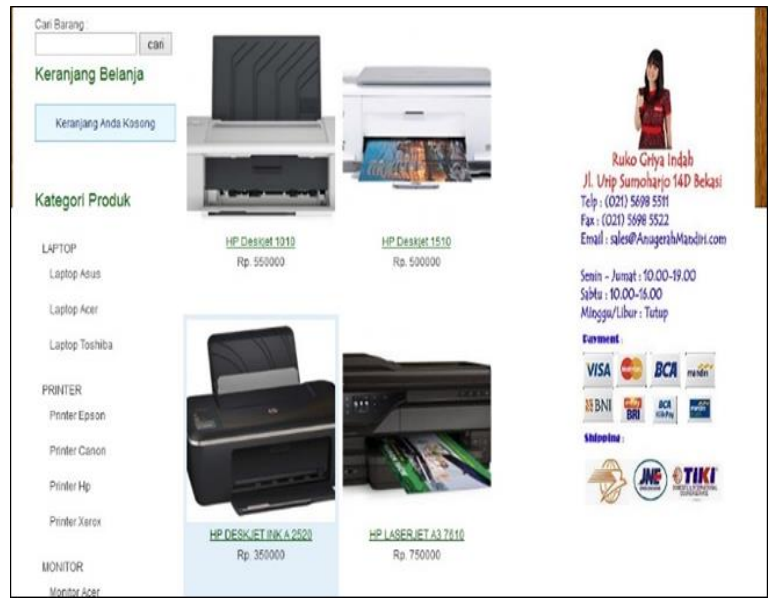

Sumber : (Kusnandar, 2011a)

Gambar 7. Halaman katalog produk

Terdapat beberapa produk yang ditawarkan serta terdapat harga dari masing-masing produk, Pembeli bisa memilih sesuai keinginan dan melakukan transaksi pembayaran. 


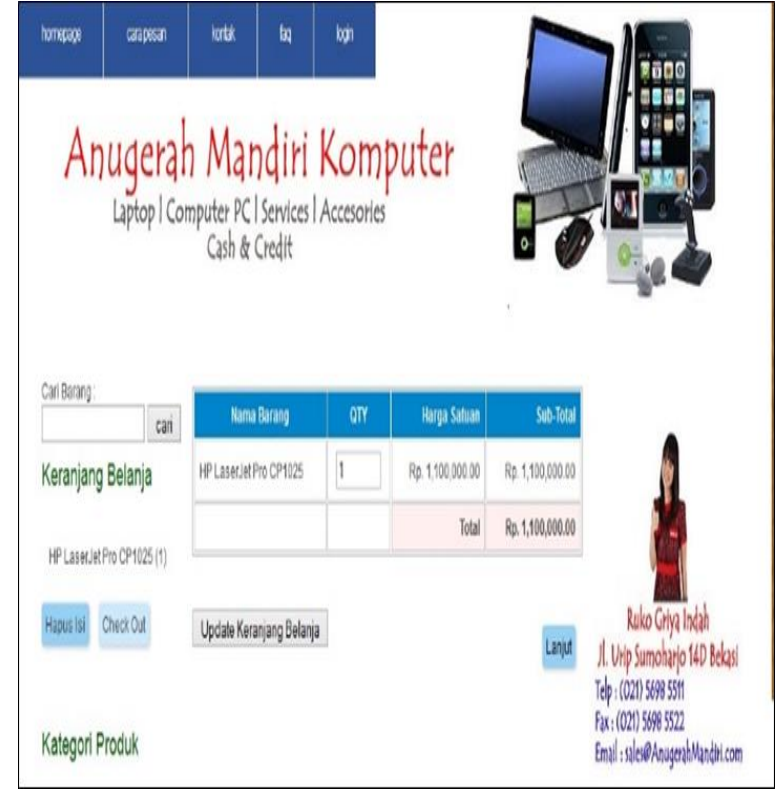

Sumber : (Kusnandar, 2011a)

Gambar 7. Halaman order produk

Tampilan dari halaman order produk berserta alamat pengiriman yang dituju dan akan tampil ketika anggota sudah menekan tombol check out dan sudah login sebagai anggota ke dalam sistem.

Proses perancangan database dilakukan dengan melihat kondisi data serta relasi dari masing table kebutuhan yang terhubung dan disimpan secara bersama-sama. Untuk menggambarkannya digunakan diagram relasi.

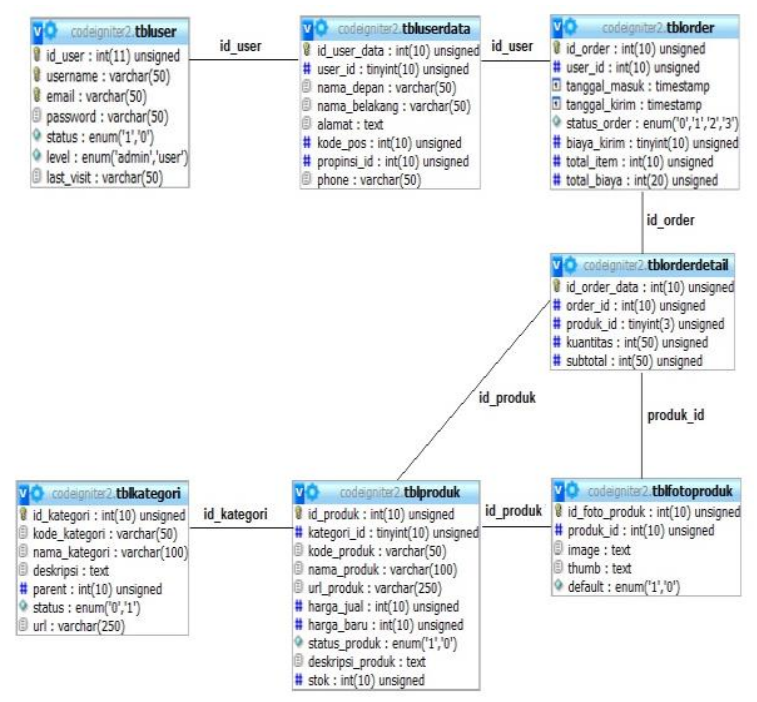

Sumber : (Supaartagorn, 2011)

Gambar 8. Diagram Relasi Sistem E-commerce

Untuk lebih mengetahui struktur direktori codeigniter pada program aplikasi E-Commerce, ada beberapa direktori dan pembagian framework.

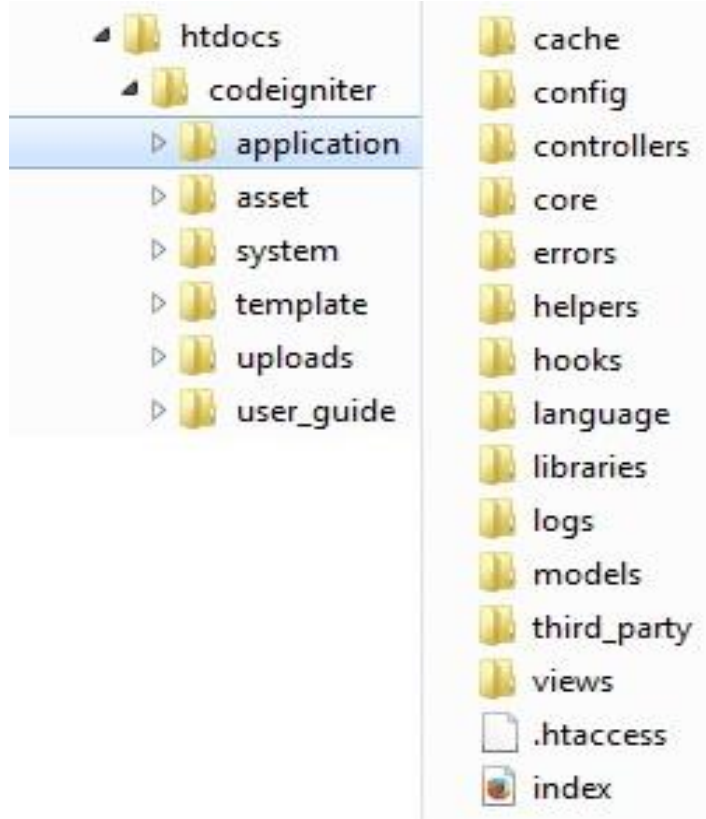

Sumber : (Maryama, 2018)

Gambar 9. Struktur direktori Framework CodeIgniter

Terdapat tiga folder utama CI, yaitu application, system dan user_guide. Dari ketiga folder tersebut, yang perlu diperhatikan lebih adalah folder application karena disinilah direktori kerja CI dan di sini pula tempat meletakkan semua file yang berkaitan dengan aplikasi yang akan dikembangkan. Dalam folder application ini terdapat beberapa subfolder dengan peran masing-masing. Beberapa subfolder inilah yang nantinya digunakan untuk mengelompokkan file aplikasi yang akan dibuat sesuai dengan fungsinya.

Dari sekian banyak subfolder yang ada, terlebih dahulu fokuskan pada empat subfolder utama, yaitu Config digunakan untuk menyimpan berbagai macam file konfigurasi sistem aplikasi yang dibuat, Controllers digunakan untuk meletakkan controller sistem aplikasi yang dibuat, Models digunakan untuk meletakkan file model sistem aplikasi yang dibuat.

Proses Pengujian ada dua yaitu pengujian alpha dan Betha Adapun pengujian yang dilakukan adalah menguji semua proses yang ada di halaman sistem E-commerce.Pengujian beta ini dilakukan dengan cara menguji langsung di tempat penelitian dengan melakukan wawancara kepada para pengguna sistem.

Berdasarkan hasil pengujian beta yang dilakukan dapat ditarik kesimpulan bahwa sistem E-commerce yang dibangun ini dapat mengatasi semua permasalahan yang ada dalam sistem manual, dapat membantu dalam operasional kerja, membantu dalam promosi dan pemasaran ke masyarakat luas sehingga dapat menekan biaya pemasaran dan meningkatkan grafik penjualan. 
Pengujian kualitas ISO 9126 ini terdiri dari dua bagian, yaitu: tingkat kualitas masing-masing aspek berdasarkan empat karakteristik ISO 9126. Dari 5 responden yang mengisi kuesioner dapat diukur dengan menggunakan rumus sebagai berikut:

$$
\% \text { Skor Aktual }=\frac{\text { Skor } \text { Aktual }}{\text { Skor Ideal }} * 100 \%
$$

\section{Keterangan:}

Skor aktual adalah jawaban seluruh responden atas kuesioner yang telah diajukan. Skor ideal adalah nilai tertinggi atau semua responden diasumsikan memilih jawaban dengan skor tertinggi.

Tabel 5. Hasil pengujian kualitas

\begin{tabular}{clll}
\hline Aspek & $\begin{array}{c}\text { Skor } \\
\text { Aktual }\end{array}$ & $\begin{array}{c}\text { Skor } \\
\text { Ideal }\end{array}$ & \multicolumn{1}{c}{ Kriteria } \\
\hline $\begin{array}{c}\text { Functionali } \\
\text { ty }\end{array}$ & 127 & 150 & Sangat Baik \\
\hline Relaibility & 99 & 125 & Baik \\
\hline Usability & 161 & 200 & Baik \\
\hline Effiecency & 48 & 50 & Baik \\
\hline Total & 435 & 525 & \\
\hline Sumber : (Kusnandar, 2011a) &
\end{tabular}

Proses pengujian dapat disimpulkan bahwa tingkat kualitas prototipe sistem informasi eksekutif ini secara keseluruhan dalam kriteria Baik, dengan persentase 84\%. Aspek kualitas tertinggi adalah berdasarkan aspek efficiency dengan persentase sebesar 96\%, sedangkan aspek kualitas terendah adalah dari aspek Reliability dengan persentase $79,2 \%$.

\section{KESIMPULAN}

Berdasarkan hasil pengujian alpha, sistem Ecommerce yang dikembangkan dapat berjalan dengan baik dan kebutuhan fungsional sistem pun dapat digunakan. Hasil pengujian beta, sistem $E$ commerce yang dibangun ini dapat mengatasi semua permasalahan yang ada dalam sistem manual, dapat membantu dalam operasional kerja, membantu dalam promosi dan pemasaran ke masyarakat luas sehingga dapat menekan biaya pemasaran dan meningkatkan grafik penjualan.

Pengujian kualitas system dengan ISO 9126 dari 5 (Lima) responden diperoleh hasil yaitu Aspek Functionality berkriteria Sangat Baik, Aspek Reliability berkriteria Baik, Aspek Usability berkriteria Baik dan Aspek Efficiency berkriteria Sangat Baik.

\section{REFERENSI}

Baird, C. H., \& Parasnis, G. (2011). From social media to social customer relationship management. Strategy and Leadership. https://doi.org/10.1108/108785711111615 07

Brown, C. H., Gould, D., \& Foster, S. (2016). A Framework for Developing Contextual Intelligence (CI). The Sport Psychologist. https://doi.org/10.1123/tsp.19.1.51

Dijkman, R. M., Sprenkels, B., Peeters, T., \& Janssen, A. (2015). Business models for the Internet of Things. International Journal of Information Management.

https://doi.org/10.1016/j.ijinfomgt.2015.07. 008

E-Commerce and E-Business. (2012). In Information and Communication Technology in Organizations: Adoption, Implementation, Use and Effects. https://doi.org/10.4135/9781446211519.n 8

Gebert, H., Geib, M., Kolbe, L., \& Brenner, W. (2003). Knowledge-enabled customer relationship management: Integrating customer relationship management and knowledge management concepts[1]. Journal of Knowledge Management. https://doi.org/10.1108/136732703105054 21

Kartikasari, D., Arifin, Z., \& Hidayat, K. (2013). Pengaruh Perilaku Konsumen Terhadap Keputusan Pembelian. Jurnal Administrasi Bisnis.

Kusnandar, T. (2011a). PENERAPAN CRM DENGAN SISTEM INFORMASI BERBASIS WEB UNTUK KEPUASAN PELANGGAN. JURNAL COMPUTECH \& BISNIS, 5(1), 6-13.

Kusnandar, T. (2011b). PENERAPAN CRM DENGAN SISTEM INFORMASI BERBASIS WEB UNTUK KEPUASAN PELANGGAN. JURNAL COMPUTECH \& BISNIS.

Lewis, P. J. (2008). Rich picture building in the soft systems methodology. European Journal of Information Systems. https://doi.org/10.1057/ejis.1992.7

Maryama, S. (2018). Penerapan E-Commerce Dalam Meningkatkan Daya Saing Usaha. 
Liquidity.

https://doi.org/10.32546/lq.v2i1.132

Rahmidani, R. (2015). Penggunaan E-Commerce Dalam Bisnis Sebagai Sumber Keunggulan Bersaing Perusahaan. Penggunaan ECommerce Dalam Bisnis Sebagai Sumber Keunggulan Bersaing Perusahaan.

Supaartagorn, C. (2011). PHP Framework for Database Management Based on MVC Pattern. International Journal of Computer Science and Information Technology. https://doi.org/10.5121/ijcsit.2011.3219

Ulfah, F., \& Rahardjo, S. T. (2013a). Analisis Pengaruh Implementasi Manajemen Kualitas. Diponegoro Journal of Management, 2(2), 164-178.
Ulfah, F., \& Rahardjo, S. T. (2013b). Analisis Pengaruh Implementasi Manajemen Kualitas. Studi Manajemen Dan Organisasi.

Walch, R. E. (2009). Electronic commerce. In Key Aspects of German Business Law (Fourth Edition): $\quad A \quad$ Practical Manual. https://doi.org/10.1007/978-3-540-685777_24 